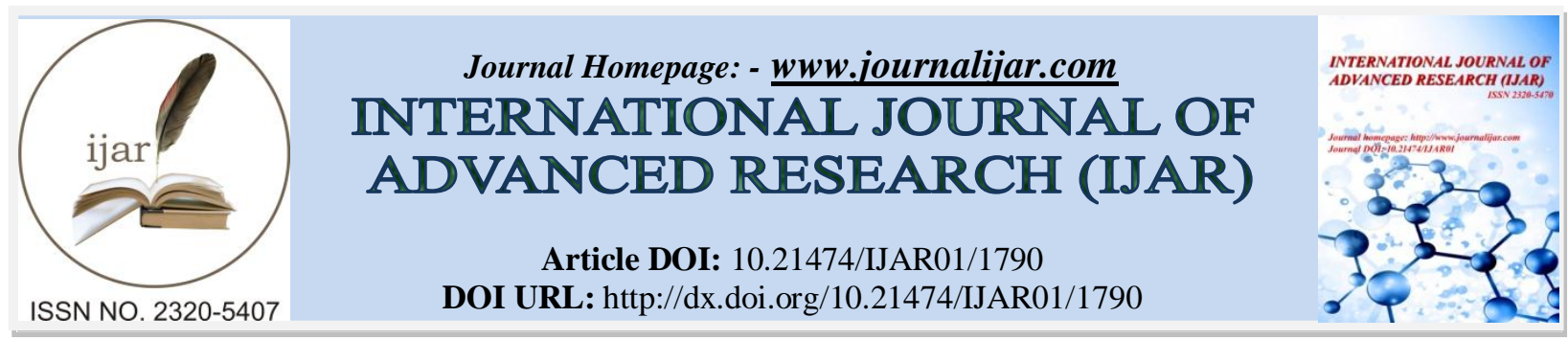

RESEARCH ARTICLE

\title{
STUDY OF ASYMMETRIC DIMETHYL ARGININE (ADMA) AND ANTI CYCLIC CITRULINATED PEPTIDE (ANTI-CCP) IN IRAQI PATIENTS WITH PSORIASIS VULGARIS.
}

\section{Israa A.Abdul Kareem MBChB ,MS.c,FICMS ${ }^{1}$, Mohammed I. Hamzah Ph.D ${ }^{2}$, Iqbal Ghalib Farhood MBChB ,FICMS ${ }^{3}$ and Muna Mhdi Hasan BSc ${ }^{4}$.}

1. Chemical pathology, College of pharmacy, Al-Nahrain University.

2. Clinical chemistry, College of Medicine, Al-Nahrain University.

3. Medicine, Dermatology \& Venereology, College of Medicine, -Nahrain University .

4. Diploma Clinical chemistry, College of Medicine, Al-Nahrain University.

\section{Manuscript Info}

Manuscript History

Received: 12 August 2016

Final Accepted: 22 September 2016

Published: October 2016

Key words:-

Psoriasis vulgaris, antiCCP and ADMA.

\section{Abstract}

Background:- Psoriasis is a common chronic, inflammatory, proliferative skin disease that generally presents as chronic sharply demarcated, dull red, scaly plaques, particularly on extensor prominences and the scalp. ADMA is a naturally occurring chemical found in blood plasma. It is a metabolic by-product of continual protein modification processes in the cytoplasm of all human cells. ADMA interferes with L-arginine in the production of nitric oxide, a key chemical involved in normal endothelial function and, by extension, cardiovascular health. Anti-cyclic citrullinated peptides (anti-CCP) are highly specific diagnostic and prognostic markers for rheumatoid arthritis (RA). They have been also found in psoriatic arthritis (PsA), with controversies as regards clinical and radiological associations.

Objectives:- To estimate level of anti-cyclic citrullinated peptide and asymmetric dimethyl arginine in sera of Iraqi patients with psoriasis vulgaris compared to healthy controls.

Patients / Methods:- Fourty (40) psoriasis patients were recruited from the dermatology Outpatient clinic in Al-Imamain Al-Kadhimain city hospital from December of 2014 to summer of 2015.Patients body mass index ( BMI ) and waist circumference (WC) were recorded. Fasting serum samples were obtained on enrolment. All the patients did not receive any treatment (locally or systemically), for at least 20 days before enrolment. Age, sex and ( BMI ) matched with fourty(40) healthy controls were also recruited. Serum ADMA \& anti CCP levels were estimated using an Enzyme-Linked Immunosorbant Assay ( ELISA ) technique (ADMA ELISA Assay Kit-Eagle Biosciences)and for ant-CCP(Anti CCP ELISA Genway GWB-521226). The patients group were subdivided into two groups according to the diseases severity, into mild to moderate psoriasis ,group and severe psoriasis group.

Results:- Serum levels of anti-CCP and ADMA were statistically significant elevated in the patients group compared to healthy controls $(\mathrm{p}<0.01)$. Also serum levels of ADMA statistically significant 
increased in in severe psoriasis compared to mild-to moderate psoriasis $(\mathrm{p}<0.05)$.

Conclusions:- These data support the view that serum anti-CCP and ADMA are involved in the pathogenesis of psoriasis, possibly by induction and maintenance of psoriatic lesion. serum ADMA levels of psoriasis patients may be an indicator of the disease severity levels of psoriasis patients may be an indicator of the disease severity.

Copy Right, IJAR, 2016,. All rights reserved.

\section{Introduction:-}

Psoriasis has been considered to be an autoimmune disease governed by responses of autoreactive $\mathrm{T}$ cells to presumptive autoantigens, such as cytokeratin 17 peptides residing in the skin (1). As an alternative explanatory model, pathophysiologic mechanisms involving, e.g., natural killer cells and mimicking autoimmunity have been strongly advocated (2). Up to $40 \%$ of all patients with psoriasis are assumed to be simultaneously affected by psoriatic arthritis (3). Anti-cyclic citrullinated peptide (anti-CCP) antibodies have been recognized as a highly sensitive marker for rheumatoid arthritis (RA), allowing detection of the disease in 58-80\% of cases (4). In contrast, _98\% of healthy individuals do not have detectable anti-CCP. Moreover, anti-CCP titer has been shown to be an early (5) prognostic marker to predict a severe course of RA (6). Recently it has been observed that anti-CCP antibodies may also occur in patients with psoriatic arthritis, with a detection rate of $7.8-15.7 \%(7,8)$. The group of citrullinated protein/peptide antibodies has also been referred to as antifilaggrin antibodies (4). These were originally detected in RA sera by indirect immunofluorescence using rat esophagus epithelium and the cornified layer of human skin (and were initially erroneously called antikeratin antibodies) as well as in human buccal mucosal cells (so-called antiperinuclear factor).Psoriasis vulgaris is a multifactorial heritable disease characterized by severe inflammation resulting in poorly differentiated, hyperproliferative keratinocytes. It is including genetic background, environmental factors, and vascular and immune system disturbances. Current research is dominated by the hypothesis that an immunological disorder with inflammatory reaction, mediated through Tlymphocytes, plays a key role in the pathogenesis of psoriasis [9].The characteristic histological features of the disease are epidermal hyperproliferation and infiltration of both dermis and epidermis by inflammatory cells including neutrophils, lymphocytes, macrophages and mast cells. Interactions between infiltrating $\mathrm{T}$ cells and skin resident cells (keratinocytes, fibroblasts, endothelial cells) are often mediated by the synthesis and release of different proinflammatory cytokines [10].

Nitric oxide (NO) is reported to be an important mediator of vascular tone. Asymmetric dimethylarginine (ADMA) has been shown to be the main endogenous inhibitor of NO synthase and it regulates NO formation. High ADMA levels have been shown to be related to disorders causing vascular inflammation, such as hypertension, hypercholesterolemia, atherosclerosis, chronic heart failure, stroke, and sepsis. Therefore, ADMA is considered to be associated with endothelial dysfunction. Furthermore, ADMA is considered to be a predictive marker of mortality in critically ill patients (11-1ㄴ). Hence, this study was carried out to evaluate asymmetric dimethyl arginine (ADMA) and anti cyclic citrulinated peptide (CCP) in patients with psoriasis.

\section{Subjects , Material and Methods:- Subjects:-}

This study comprised Fourty (40) consecutive patients of psoriasis were recruited from the dermatology outpatient clinic in in Al-Imamain Al-Kadhimain city hospital from December of 2014 to summer of 2015 All the patients were subjected to detailed examination including the elicitation of dermatological and psychiatric complaints. The diagnosis was made clinically, based on the presence of characteristic plaque-type psoriatic lesions. All the patients were asked to provide socio-demographic data, medical history, and family history. Other questions included the duration of disease, age of onset of the disease, any treatment taken and use of psychotropic drugs. Dermatological examination, hairs, mucosal involvement and nail changes were recorded. The patients group were subclassified to two groups

according to the diseases severity, severity index ( PASI ) into, mild-to-moderate psoriasis group and severe psoriasis group. Fourty (40) healthy age and sex matched volunteers with no family history of psoriasis were included in the study as a control group. The purpose and nature of the study were explained to all subjects. All included subjects have consented to be enrolled in this study. 


\section{Exclusion Criteria:-}

Pregnant ladies,Presence of other autoimmune disease like Hashimoto's thyroiditis, diabetes mellitus, SLE, liver disease, renal disease, recent history of cardiovascular disorder, hypertension, neurological disease, or, obese subjects with history of acute or chronic infections, were excluded from the study. Moreover, patients who had received oral or topical antipsoriatic therapy within one month were not included in the study. On treatment that affect immunity.

\section{Blood Sampling:-}

Blood samples $(10 \mathrm{ml})$ were collected from patients and control subjects in serum separator vacutainers ( BD Vacutainer Systems, Plymouth, UK). Sera were separated and immediately stored at $-20^{\circ} \mathrm{C}$ until analysis.

\section{Serum anti-CCP \& ADMA Measurements:-}

The quantitative determination of ADMA \& anti CCP levels were conducted by an Enzyme-Linked Immunosorbant Assay ( ELISA ) technique, using a commercial available kit, Every sample was run in duplicate, measurements differed by less than $10 \%$, and the mean value was calculated and used for statistical analysis.

\section{Statistical analysis:-}

All data were coded and entered using the program statistical package for social sciences (SPSS) version 20 under windows XP. Descriptive data was summarized using mean, standard error (SD).P values $<0.05$ were considered statistically significant.

\section{Results:-}

Serum levels of anti-CCP and ADMA were estimated in 40 patients with Psoriasis patients, $(23$ sever psoriasis \& 17 mild to moderate psoriasis) compared with 40 healthy control group, age and sex matched.

As expected, the patients had significantly higher level of anti-CCP levels than the healthy controls $(\mathrm{p}<0.01)$.. but there was not found a significant difference within psoriasis patients( $p>0.05)$,as shown in figure(1-1) and table(11).

The concentrations of serum level ADMA, are presented in Table (1-1). are significantly higher in psoriasis patients as compared with normal subjects( $\mathrm{p}<0.01)$. As shown in figure $(1-2)$, Also serum levels of ADMA statistically significant increased in in severe psoriasis compared to mild-to moderate psoriasis $(\mathrm{p}<0.05)$.

.see figure(1-2).

The levels of anti-CCP and ADMA) in normal healthy subjects and psoriasis subjects was depicted in Table 1 .

Table 1-1:- The Anthropometric and biochemical variables among the three studied groups.

\begin{tabular}{|c|c|c|c|l|}
\hline Parameters & Control & $\begin{array}{l}\text { Mild to Moderate } \\
\text { Psoriasis }\end{array}$ & Severe Psoriasis & P(ANOVA)-(T-Test) \\
\hline NO. & $\mathbf{4 0}$ & $\mathbf{1 7}$ & $\mathbf{2 3}$ & $\ldots \ldots \ldots \ldots \ldots$ \\
\hline Anti-CCP $(\mathbf{U} / \mathbf{m l})$ & $\mathbf{9 . 2 \pm 7 . 3}$ & $\mathbf{6 5 . 6 3} \pm \mathbf{2 6 . 5 3}$ & $\mathbf{7 6 . 3 1} \pm \mathbf{5 9 . 0}$ & $\begin{array}{l}\text { severe x mild-moderate: } \mathrm{p}>0.05 \\
\text { psoriasis x C: P }<0.01\end{array}$ \\
\hline ADMA $(\boldsymbol{\mu m o l} / \mathbf{l})$ & $\mathbf{0 . 4 6} \pm \mathbf{0 . 0 6}$ & $\mathbf{0 . 8 7} \pm \mathbf{0 . 0 7}$ & $\mathbf{1 . 4 9} \pm \mathbf{0 . 0 9}$ & $\begin{array}{l}\text { severe x mild-moderate: } \mathrm{P}<0.05 \\
\text { psoriasis x C: } \mathrm{p}<0.01\end{array}$ \\
\hline
\end{tabular}

Values are Mean \pm SD, $\mathrm{X}=\mathrm{VS}$. 


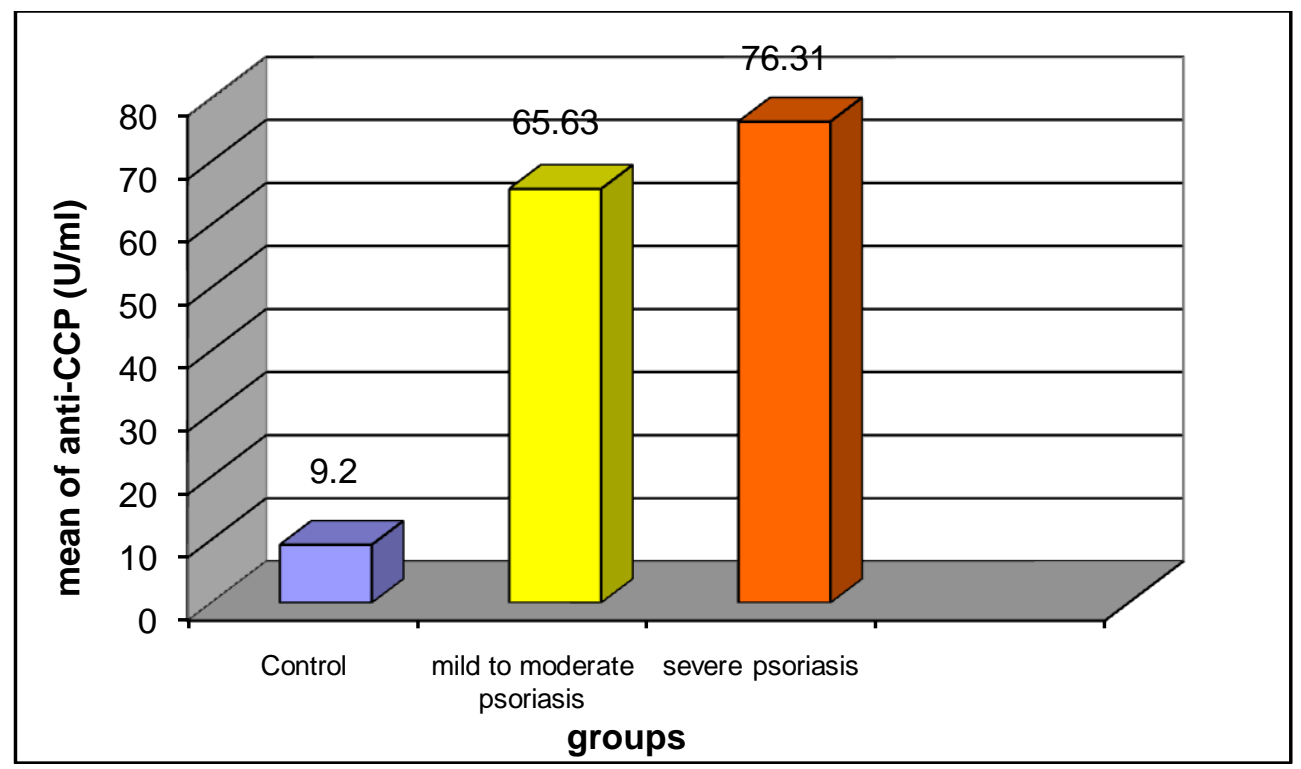

Figure 1-1:- Serum levels of anti-CCP in patients with psoriasis vulgaris compared to healthy controls.

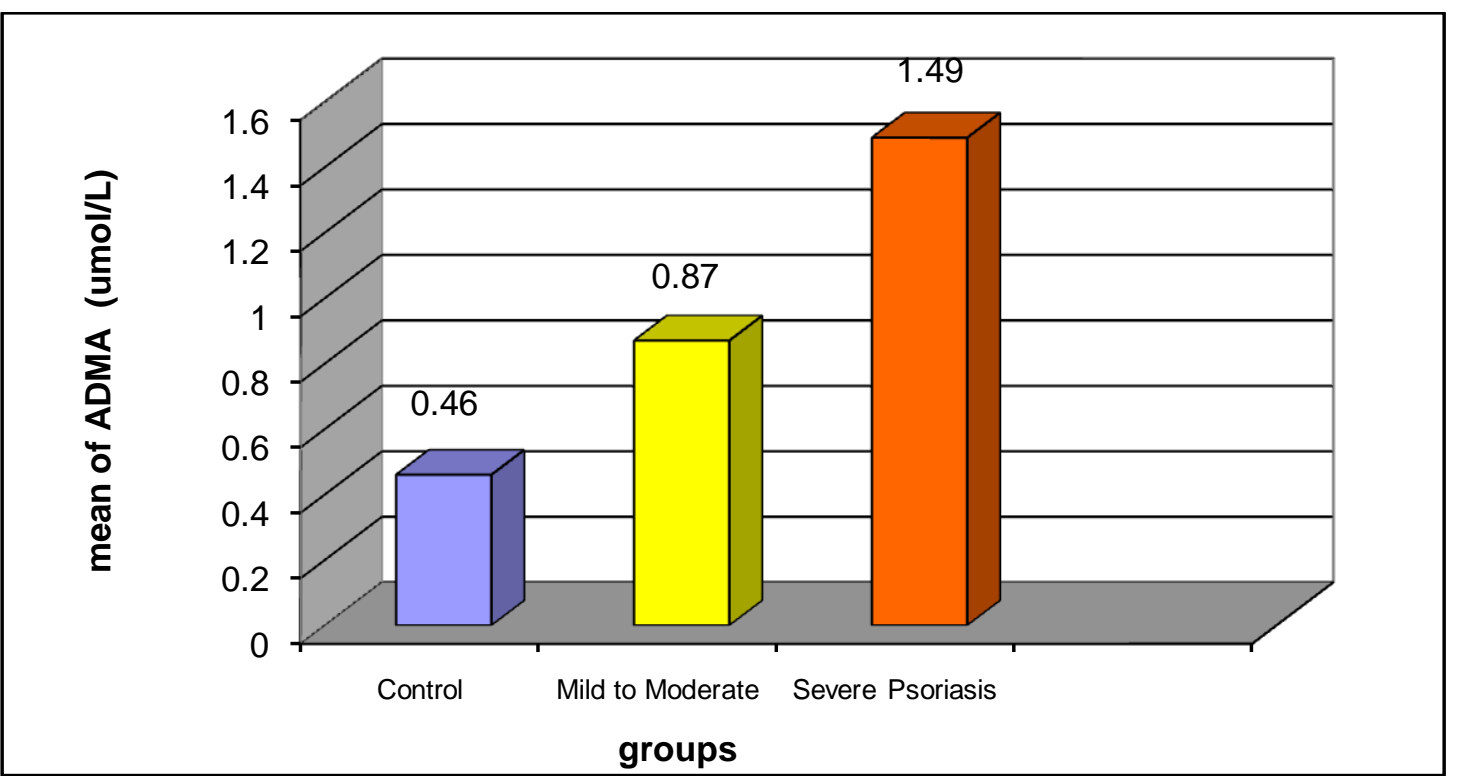

Figure 1-2:- Serum levels of ADMA in patients with psoriasis vulgaris compared to healthy controls

\section{Discussion:-}

Psoriasis has been considered to be an autoimmune disease governed by responses of autoreactive $\mathrm{T}$ cells to presumptive autoantigens, such as cytokeratin 17 peptides residing in the skin (15). As an alternative explanatory model, pathophysiologic mechanisms involving, e.g., natural killer cells and mimicking autoimmunity have been strongly advocated (16). Up to $40 \%$ of all patients with psoriasis are assumed to be simultaneously affected by psoriatic arthritis (17).

Psoriasis is a common inflammatory disease of the skin and joints. Its aetiology remains unknown,however, it has been linked to complex interactions between predisposing genes and the environment. The pathophysiology of psoriasis is characterized by epidermal hyperproliferation, enhanced antigen presentation, T helper ( Th -1) cytokine production, T cell expansion, and angiogenesis. Tremendous advances in understanding of this disorder has led to the development of novel therapeutics and the FDA approval of more systemic agents for its treatment in the last 5 
years than in the previous 50 years combined. Improved understanding of the pathogenesis of psoriasis has led to epidemiologic studies that have contributed towards further characterizing its natural history (18). In this study we focused on the impact of serum levels of anti-CCP and ADMA in psoriasis vulgaris In Iraqi patients which are of major clinical relevance to the clinician.

The results of our study showed that serum level ADMA, are presented in Table (1-1). are significantly higher in psoriasis patients as compared with normal subjects this results agree with other results done by ("O.Bilgic et al.,2015)(19) who said that Plasma ADMA levels were significantly higher in the patients with psoriatic patients compared with controls. Other study also showed that Plasma ADMA level was found significantly higher in a small sample of 22 patients with PsA compared with that in 35 healthy controls (20). The results of this study also showes an increment in the investigated ADMA,a significant increase in serum level of ADMA in severe psoriasis than in mild-to-moderate ones.

Nitric oxide (NO) is the elusive mediator that causes vascular dilatation. Endothelial dysfunction occurs when the biological functions of NO are impaired (21). Asymmetric dimethylarginine (ADMA) is a competitive inhibitor of NO synthesis (22).

The present study showed that higher level of anti-CCP levels than the healthy controls $(p<0.01)$.this result agree with other result done by Raik etal.,2006( 23 ),but there was not found a significant difference within psoriasis patients( $(\mathrm{p}>0.05)$,as shown in figure(1-1) and table(1-1).In Conclusions These data support that serum anti-CCP and ADMA are involved in the pathogenesis of psoriasis, possibly by induction and maintenance of psoriatic lesion. serum ADMA levels of psoriasis patients may be an indicator of the disease severity levels of psoriasis patients may be an indicator of the disease severity.

\section{References:-}

1. Bockelmann R, Horn T, Gollnick H, Bonnekoh B. Interferon - dependent in vitro model for the putative keratin 17 autoimmune loop in psoriasis: exploration of pharmaco- and gene-therapeutic effects. Skin Pharmacol Physiol .2005;18:42-54.

2. Bos JD, de Rie MA, Teunissen MBM, Piskin G. Psoriasis: dysregulation of innate immunity. Br J Dermatol. 2005;152: 1098-107.

3. Winterfield LS, Menter A, Gordon K, Gottlieb A. Psoriasis treatment: current and emerging directed therapies. Ann Rheum Dis. 2005;64 (Suppl II):87-90.

4. Sebbag M, Chapuy-Regaud S, Auger I, Petit-Texeira E, Clavel C, Nogueira L, et al. Clinical and pathophysiological significance of the autoimmune response to citrullinated proteins in rheumatoid arthritis. Joint Bone Spine. 2004;71:493-502.

5. Nielen MM, van Schaardenburg D, Reesink HW, van de Stadt RJ, van der Horst-Bruinsma IE, de Koning MH, et al. Specific autoantibodies precede the symptoms of rheumatoid arthritis: a study of serial measurements in blood donors. Arthritis Rheum. 2004;50:380-6.

6. Lindqvist E, Eberhardt K, Bendtzen K, Heinegard D, Saxne T. Prognostic laboratory markers of joint damage in rheumatoid arthritis. Ann Rheum Dis .2005;64:196-201.

7. Vander Cruyssen B, Hoffman IEA, Zmierczak H, van den Berghe M, Kruithof E, De Rycke L, et al. Anticitrullinated peptide antibodies may occur in patients with psoriatic arthritis. Ann Rheum Dis. 2005;64:1145-9.

8. Bogliolo L, Alpini C, Caporali R, Scire CA, Moratti R, MontecuccoC. Antibodies to cyclic citrullinated peptides in psoriatic patients. J Rheumatol 2005;32:511-5.

9. Nograles K., Davidovici B., Krueger J. New insights in the immunologic basis of psoriasis. Semin Cutan Med Surg. 2010; 29(1):3-9.

10. Krueger G. and Ellis C. Psoriasis - recent advances in understanding its pathogenesis and treatment. J Am Acad. Dermatol. 2005 ; 53: 94- 100.

11. Rowe A, Farrell AM, Buncer CB. Constitutive endothelial and inducible nitric oxide synthase in inflammatory dermatoses. Br J Dermatol. 1997;13:18-23.

12. Moncada S, Palmer RMJ, Higgs EA. Nitric oxide: physiology, pathophysiology and pharmacology.Pharmacol Rev. 1991;13:109-134.

13. Böger RH. Live and let die: asymmetric dimethylarginine and septic shock. Crit Care. 2006;13:169.

14. Tosun M, Apuhan T. Asymmetric dimethylarginine levels in allergic rhinitis and nasal polyposis. Turkish J Med Sci. 2013;13:455-458. 
15. Bockelmann R, Horn T, Gollnick H, Bonnekoh B. Interferon-_dependent in vitro model for the putative keratin 17 autoimmune loop in psoriasis: exploration of pharmaco- and gene-therapeutic effects. Skin Pharmacol Physiol .2005;18:42-54.

16. Bos JD, de Rie MA, Teunissen MBM, Piskin G. Psoriasis: dysregulation of innate immunity. Br J Dermatol .2005;152: 1098-107.

17. Winterfield LS, Menter A, Gordon K, Gottlieb A. Psoriasis treatment: current and emerging directed therapies. Ann Rheum Dis. 2005;64 (Suppl II):87-90.

18. Stephen K. and Gelfand M. Update on the Natural History and Systemic Treatment of Psoriasis. Adv Dermatol. 2008 ; 24: 171-196.

19. "O.Bilgic,Hilmi cevdet,Hatice Baran,Ali Unlu Serum homocysteine, asymmetric dimethyl arginine (ADMA) and other arginine-NO pathway metabolite levels in patients with psoriasis, PubMed , 307(5) • February 2015 DOI: $10.1007 / \mathrm{s} 00403-015-1553-3$.

20. F. Atzeni, P. Sarzi-Puttini, S. Sitia et al., "Coronary flow reserveand asymmetric dimethylarginine levels: new measurements for identifying subclinical atherosclerosis in patients withpsoriatic arthritis," Journal of Rheumatology. 2011; vol. 38, no. 8, pp.1661-1664.

21. M. Anderssohn, E. Schwedhelm, N. L"uneburg, R. S. Vasan, and R. H. B"oger, "Asymmetric dimethylarginine as a mediator of vascular dysfunction and a marker of cardiovascular disease and mortality: an intriguing interaction with diabetes mellitus," Diabetes and Vascular Disease Research. 2010; vol. 7, no. 2, pp. 105-118.

22. R. H. B"oger, "Asymmetric dimethylarginine, an endogenous inhibitor of nitric oxide synthase, explains the "L-arginine paradox" and acts as a novel cardiovascular risk factor," Journal of Nutrition.2004; vol. 134, no. 10.

23. Raik Böckelmann MD,Harald Gollnick MD, Bernd Bonnekoh MD. Anti-cyclic citrullinated peptide antibodies in psoriasis patients without arthritis, Journal of Rheumatology. May 2006 Volume 54, Issue 5 Pages 17011702 . 